\title{
Das Gleiche in Grün
}

Woher kommt dieser Ausdruck? Wie sind unsere Vorfahren ausgerechnet auf grün gekommen, hat das etwas mit grün sprießenden Pflanzen oder sogar mit Fröschen zu tun? Und tatsächlich, ein Laubfrosch hat sich in unseren Sprachgebrauch gemogelt. Doch handelt es sich nicht um einen quakenden, lebendigen Laubfrosch, sondern um ein grünes Gefährt, nämlich den ersten Kleinwagen der Firma Opel aus den 1920er Jahren, der im Volksmund Opel Laubfrosch hieß. Kurz bevor dieses Auto die deutschen Straßen eroberte, hatte der französische Autobauer Citroën ein ganz ähnliches, allerdings zitronengelbes Auto, auf den Markt gebracht. Die auffällige Ähnlichkeit der beiden Modelle veranlasste das französische Unternehmen, Opel vor Gericht des Plagiats zu bezichtigen. Das Landesgericht Berlin wies die Klage allerdings ab, unter anderem weil das deutsche Auto grün statt gelb war und deshalb keine Gefahr bestand, die beiden Wagen zu verwechseln. Trotzdem ist seither der Ausspruch „das ist doch das Gleiche in Grün" in aller Munde.

\section{Der Buchstabe der richtigen Antwort ist}

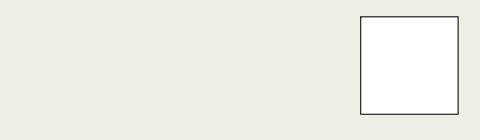

\begin{tabular}{l} 
Name \\
Straße, Nr. \\
\hline PLZ, Ort
\end{tabular}

Was ich noch sagen wollte ...

Coupon bitte ausfüllen und abschicken an

Springer Medizin, Urban \& Vogel GmbH

Redaktion IM FocUs ONKOLOGIE - Quiz 5/2012

Aschauer Straße 30 • 81549 München

Ist die Geschichte wahr?
A Ja
B Nein

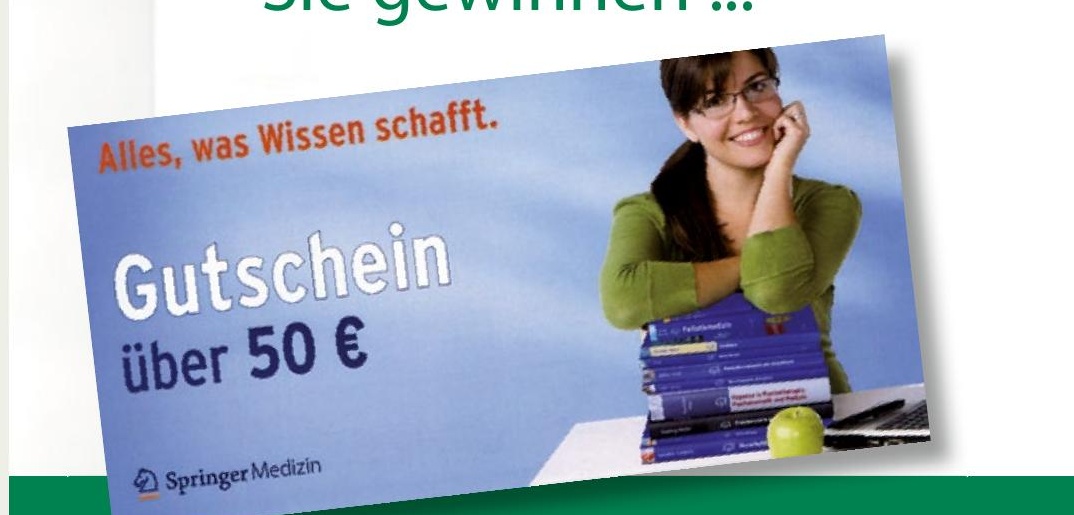

Unter den richtigen

Einsendungen verlosen wir drei Gutscheine über 50 Euro, die Sie für ein beliebiges Springer-Buch einlösen können.

Einsendeschluss ist der 18.06.2012
Lösung des Quiz 3/2012 Richtig war: B

Die Gewinne gehen an:

I. Rösinger, 73730 Esslingen

R. Skock-Lober, 19073 Wittenförden

C. Gröger, 04720 Döbeln/Sachsen

Herzlichen Glückwunsch! 